\title{
Potential methodological influences on the determination of particle retention efficiency by suspension feeders: Mytilus edulis and Ciona intestinalis
}

\author{
Peter J. Cranford ${ }^{1, *}$, Tore Strohmeier ${ }^{2}$, Ramon Filgueira ${ }^{3}$, Øivind Strand ${ }^{2}$ \\ ${ }^{1}$ Department of Fisheries and Oceans, Bedford Institute of Oceanography, 1 Challenger Dr., Dartmouth, \\ Nova Scotia B2Y 4A2, Canada \\ ${ }^{2}$ Institute of Marine Research, PO Box 1870 Nordnes, 5817 Bergen, Norway \\ ${ }^{3}$ Marine Affairs Program, Dalhousie University, 1355 Oxford St., Halifax, Nova Scotia B3H 1R2, Canada
}

\begin{abstract}
The retention efficiency (RE) of suspension-feeding bivalve molluscs depends on particle size and is generally assumed to decline below a maximum retention of particles larger than 3 to $7 \mu \mathrm{m}$. Previous suggestions that the RE spectrum of mussels Mytilus edulis can exhibit variability, possibly as a result of physiological regulation, have been attributed to artifacts associated with the indirect method. The possibility that variable physical properties of seston particles and/or miscalculations can result in inaccurate RE measurements was examined using 3 methodologies (static, flow-through and a new approach based on the static method) and 3 particle sources (natural seston, algal cell monocultures and clay). Measurements obtained with the static method varied depending on the selected sampling interval. However, this artifact can be removed using frequent sampling and a regression analysis approach. Accurate RE measurements can be obtained with the flow-through method when feeding behaviour is flow independent. For all particle suspensions and methods, mussels from the study site in Lysefjord, Norway, had a maximum RE for particles $>8-11 \mu \mathrm{m}$ (1 to 5 September 2015). The RE for smaller particles declined gradually, with $50-60 \%$ retention of $4 \mu \mathrm{m}$ particles and $30-40 \%$ retention of $2 \mu \mathrm{m}$ particles. Differences in the RE size spectra of mussels and tunicates Ciona intestinalis, collected and measured at the same site, further indicated that RE was not influenced by potentially confounding methodological factors. Assumptions regarding the RE spectrum of bivalves have contributed to many conclusions on their ecosystem interactions. The reliability of clearance rate measurements obtained using the indirect method can only be assured if the effective retention of tracer particles is confirmed and not assumed.
\end{abstract}

KEY WORDS: Filter feeding $\cdot$ Retention efficiency $\cdot$ Clearance rate $\cdot$ Mytilus edulis $\cdot$ Ciona intestinalis $\cdot$ Physiological regulation $\cdot$ Feeding mechanism

\section{INTRODUCTION}

Dense populations of wild and cultured bivalve molluscs can play an important role in coastal marine ecosystems through the provision of ecological services and possibly by way of negative environmental effects (Shumway 2011). This role is largely linked to the population's capacity to capture suspended par-

*Corresponding author: peter.cranford@dfo-mpo.gc.ca ticulate matter through suspension feeding (Cranford et al. 2011). Particle clearance rate (CR), the volume of water cleared of particles of a designated size in a given time, is commonly measured using the indirect method. This method was used to measure CRs reported in $92 \%$ of the 133 peer-reviewed publications reviewed by Cranford et al. (2011). The indirect approach is based on determining the rate of

(C) The authors and Fisheries and Oceans Canada 2016. Open Access under Creative Commons by Attribution Licence. Use, distribution and reproduction are unrestricted. Authors and original publication must be credited.

Publisher: Inter-Research · www.int-res.com 
removal of particles from a set volume or constant flow. In both cases, CR is a function of the rate that water is pumped through the gill (pumping rate, PR) and the proportion of suspended particles that are retained by the feeding apparatus (retention efficiency, RE). Coughlan (1969) outlined the fundamental assumptions of the indirect approach for estimating $\mathrm{CR}$, including the requirement that the organism retain tracer particles of a predetermined size range with known efficiency (usually 100\%). Williams (1982) subsequently showed that the observed rate of particle removal cannot easily be translated into a CR when RE is less than $100 \%$. Knowledge on the relationship between RE and particle size is therefore essential for determining accurate CRs and subsequently for interpreting ecosystem interactions with bivalve populations.

The particle RE of suspension-feeding bivalve molluscs clearly depends on particle size, and this relationship has been described as an asymptotic increase to maximum retention at particle diameters between 3 and $7 \mu \mathrm{m}$ (e.g. Haven \& Morales-Alamo 1970, Vahl 1972, Jørgensen 1974, Møhlenberg \& Riisgård 1978, Palmer \& Williams 1980, Lucas et al. 1987, Riisgård 1988). Particle retention in Mytilus edulis is reported to rapidly decrease below approximately $4 \mu \mathrm{m}$ (Møhlenberg \& Riisgård 1978), and this empirical model has become firmly established in the literature. However, several field studies have reported distinctly different RE size distributions. Strohmeier et al. (2012) showed that blue mussels $M$. edulis in a Norwegian fjord exhibited seasonally variable particle retention size spectra, with a gradual increase in RE from small to large particles and maximum RE at sizes between 7 and $35 \mu \mathrm{m}$. Changes in the RE maxima appeared to coincide with changes in the ambient particle size distribution. In addition, $\mathrm{RE}$ often declined as particle size exceeded the RE maxima. Similar results with seston diets were observed in studies of mussel filtration by Lucas et al. (1987) and Rosa et al. (2015) and have been reported for other bivalve species (Stenton-Dozey \& Brown 1992, Barillé et al. 1993). The divergence of results between laboratory and field studies raises uncertainty regarding the relative contribution of potential trophic resources to bivalve growth and suggests that a widely accepted methodological assumption for determining feeding rates (effective retention of particles larger than 3-7 $\mu \mathrm{m}$ ) may not always be valid.

Strohmeier et al. (2012) suggested that the seasonally variable $\mathrm{RE}$ of mussels in nature may indicate a high degree of physiological control of particle capture. However, the absence of a known particle capture mechanism that would fully explain all these results has contributed to a focus on identifying alternative explanations, particularly methodological errors (Rosa et al. 2015). Strohmeier et al. (2012) noted that $\mathrm{RE}$ artifacts could stem from the improper use of particle-counting instrumentation, the method for data standardization, flow variations in feeding chambers, and the disaggregation of flocculated particles in feeding chambers. In addition, Rosa et al. (2015) suggested that artifacts may result from nonspherical seston particles confounding the measurement of particle size, the escape of motile cells from capture, and/or mathematical happenstance. Presently, no definitive conclusion has been reached on whether or not RE is physiologically controlled or varies simply as a result of methodological artifacts.

The present study investigated possible sources of error in RE and CR methodologies with the objective of providing recommendations on approaches that ensure a high degree of measurement accuracy. Data obtained with these methods were also used to determine if the retention of seston particles by $M$. edulis conforms to the traditionally accepted RE size distribution (see above) or to some alternate relationship with particle size.

Variations in particle shape can influence the determination of equivalent spherical diameter (ESD) by particle analyzers and thereby cause errors in the calculation of the RE size distribution. For example, a long particle may be effectively captured despite having a relatively small ESD. The possibility of methodological artifacts arising from variations in the shape of different particle sources in natural seston was addressed by comparing RE size distributions obtained for natural seston suspensions with those from reference diets containing particles with uniform properties across their size spectra (marine clay and algal cell monocultures). In the absence of a significant particle shape effect, the RE size distribution for all experimental particle suspensions should be similar. The potential effect on RE measurements from variability in the physical properties of seston particles was also addressed by examining particle retention by species with different feeding mechanisms. Methodological artifacts introduced in the calculation of RE by the physical properties of different particles should consistently arise for a given particle suspension regardless of the particle capture mechanism. Published RE size distributions for $M$. edulis (cirri and cilia particle capture anatomy) and the vase tunicate Ciona intestinalis (mucociliary net) have both been characterized as including a rapid decline in RE below a particle size threshold (e.g. Randløv \& 
Riisgård 1979 and references in this section for mussels). Although the threshold size for maximal RE varies between these species, the shape of the RE size distribution should follow the same general pattern for both species if methodological errors were influencing the measurements. In the absence of methodological errors, changes in the shape of the RE size distributions of mussels, relative to tunicates, would reveal a higher degree of flexibility in particle retention. The relatively simple mucus net of $C$. intestinalis may be expected to produce a typical sieve retention response, with $\mathrm{RE}$ rapidly declining below the pore size of the net, while the more complex feeding apparatus of mussels may facilitate a more variable response (e.g. Ward et al. 1998, Strohmeier et al. 2012). All of the methodological validations and comparisons described herein were conducted using disaggregated particle suspensions to prevent errors that would occur if the mussel, tunicate or experimental apparatus was altering the ambient particle size distribution by means other than an active particle capture mechanism.

Measurement accuracy was assessed by comparing results obtained using 3 methods (static, flowthrough and a new approach based on the static method) and 3 different particle suspensions (natural seston, algal cell monocultures and clay). In addition, a revised static method was developed that employs a rigorous sampling approach designed to statistically assess the reliability of all measurements. RE results obtained with these different methods were compared to assess the inherent assumption that they provide similar results. The flow-through approach strictly requires that the suspension is not recirculated by the suspension feeder(s) and that the results are not flowdependent (Riisgård 1977), while the static method exponential model is expected to account for recirculation (Coughlan 1969). Both approaches are assumed to give an equivalent standardized RE size spectra, despite the fact that the flow-through method provides a near-instantaneous particle retention response, while the static method provides a cumulative response after several passes of the suspension through the filtration apparatus.

\section{MATERIALS AND METHODS}

\section{Study site, test organisms and particle suspensions}

RE measurements for blue mussels Mytilus edulis and vase tunicates Ciona intestinalis were performed between 1 and 5 September 2015 at a field station
(Måkastein) located near the head of the Lysefjord $\left(59^{\circ} 03.24 \mathrm{~N}, 6^{\circ} 837.77 \mathrm{E}\right)$. Lysefjord is located on the southwestern coast of Norway and is approximately $40 \mathrm{~km}$ long and 0.5 to $2 \mathrm{~km}$ wide, with a depth range from $13 \mathrm{~m}$ at the outer sill to a maximum of $460 \mathrm{~m}$. The mean tidal range is $0.4 \mathrm{~m}$. Seasonal variations in suspended particle matter concentrations at the study site average $3.1 \mathrm{mg} \mathrm{l}^{-1}(\mathrm{SD}=1.2$; Strohmeier et al. 2015). Mussels and tunicates were collected at the study site by divers from approximately $7 \mathrm{~m}$ depth on 22 July 2015. Mussels were initially graded to a shell length range of 49 to $62 \mathrm{~mm}$, and both species were thereafter held at $7 \mathrm{~m}$ depth at Måkastein to acclimatize to local conditions. Mussels and tunicates selected for feeding experiments ranged between 52 and $58 \mathrm{~mm}$ shell length and 74 to $96 \mathrm{~mm}$ tunic height, respectively. Three days prior to conducting feeding experiments, Velcro strips were fixed to the base of the tunic with cyanoacrylate glue to allow each tunicate to be positioned within feeding chambers.

A variety of particle suspensions were employed in this study, including 5 species of cultured algal cells, natural seston pumped from $7 \mathrm{~m}$ depth at Måkastein, and clay particles of a size distribution similar to the seston diet but containing particles of uniform shape. The algal species were chosen from available culture stocks at the Austevoll Research Station to include oval and pennate shapes based on microscopic measurements. The cultured stocks included Thalassiosira pseudonana (4.75 $\mathrm{mm}$ modal size based on laser particle counter analysis described below), Chaetoceros calcitrans $(7.25 \mu \mathrm{m})$, Skeletonema costatum $(14.25 \mu \mathrm{m})$, Tetraselmis suecica $(12.75 \mu \mathrm{m})$ and $C$. muelleri $(6.75 \mu \mathrm{m})$. Length:width ratios measured by microscopy ranged from 1.5 (C. muelleri) to 2.6 ( $S$. costatum). The clay was obtained from a natural glaciomarine deposit composed principally of kaolinite and illite that was initially dry-sieved at $63 \mu \mathrm{m}$. The unfiltered seawater for experiments with natural seston was supplied using a shallow well jet pump. High sheer forces and rapid pressure changes within the pump ensured that a disaggregated seston suspension was delivered to all experimental chambers. The clay and algal cell suspensions served as controls for the potential effects of variable particle shapes in the seston on instrument calculations of ESD and any ensuing effects on particle retention by mussels.

\section{Particle analysis}

Analysis of all particle suspensions was performed using a PAMAS field laser particle counter (Mod- 
el S4031GO) containing an HCB-LD-50/50 lightscattering sensor. This instrument provides particle counts (numbers) within a potential interval of detection between 1 and $200 \mu \mathrm{m}$ (32 size channels). The analyzer was initially set to determine the particle size distribution spanning a total range from 1 to $32 \mu \mathrm{m}$ (studies with the flow-through method) but was reduced to a detection range from 1 to $16.5 \mu \mathrm{m}$ for the remainder of the experiments. The PAMAS was factory-calibrated according to ANSI/NFPA T2.9.6 R1-1990 and ASTM F658-80 for 17 sizes of certified latex beads spanning the full range of the instrument $(1200 \mu \mathrm{m})$. The largest standard deviation detected during calibration for particle sizes in the range 1 to $40 \mu \mathrm{m}$ (12 different sizes used) was $0.52 \mu \mathrm{m}$. Instrument calibration was confirmed at the study site using certified particle size standards (Beckman Coulter latex beads; nominal 2, 5 and $10 \mu \mathrm{m}$ diameter). The PAMAS was used for both discrete sample analysis (10 $\mathrm{ml}$ water samples) and time-series analysis of particle suspensions. The latter was accomplished by programming the instrument to pump water from feeding chambers at set intervals (more details in the next subsection).

\section{Retention efficiency}

\section{Static method}

Prior to starting each experiment, 3 mussels or 7 tunicates were transferred from a holding tank to clear PVC feeding chambers $(13 \mathrm{~cm}$ height and $10 \mathrm{~cm}$ diameter; $1000 \mathrm{ml}$ volume) supplied with flowing unfiltered seawater from $7 \mathrm{~m}$ depth. The tunicates were attached to Velcro strips on the side of the chamber, while the mussels rested on a perforated shelf on the base of the chambers. Water within chambers was continually mixed by aeration in an internal airlift tube that pumped water from below the shelf up to the surface. This recirculation approach results in a low degree of turbulence. An identical chamber without any suspension feeders served as a control for sedimentation. The suspension feeders were initially left undisturbed for ca. $1 \mathrm{~h}$, until observed to be actively feeding (open siphons). The water flow to the chamber was then terminated. For experiments with natural seston, the PAMAS was immediately set to withdraw $10 \mathrm{ml}$ water samples from the chamber at $30 \mathrm{~s}$ intervals, to determine the particle size distribution, and then to return the water to the chamber as the next sample was acquired. For studies with suspensions containing clay or algae cells, a small volume $(<10 \mathrm{ml})$ of a concentrated particle stock suspension was added to the unfiltered seawater in each chamber immediately after the seawater flow was terminated. The particles were allowed to mix for $1 \mathrm{~min}$, and then the PAMAS was started for semi-continuous analysis, as for the natural seston. A Turner Cyclops chlorophyll a fluorometer, inserted through the top of the static chambers, was used to monitor the decline in microalgal concentrations throughout each experiment. The incubation was terminated when the fluorescence signal declined to a constant value, which generally required $30 \mathrm{~min}$. These fluorometer data were not employed in the following RE calculations, as they do not provide information on fluorescent particle size.

A suspension feeder pumping at a constant rate in a static chamber will remove particles at a rate that is a function of the concentration of particles in the chamber and the capacity of the filter feeder to retain these particles (RE). As the suspension feeder continuously removes particles, the concentration $(C)$ in the chamber will decrease in an exponential form, resulting in a linear decline in $\ln C$ over time (Coughlan 1969). Semi-continuous (30 s interval) particle counting with the PAMAS analyzer monitored this progressive particle reduction and the RE for each particle size, and for any given elapsed time, $\mathrm{RE}_{\text {size, } t}$ is proportional to:

$$
\mathrm{RE}_{\mathrm{size}, t} \propto \ln \left(C_{\mathrm{size}, 0} / C_{\mathrm{size}, t}\right)
$$

where $C_{\text {size, } t}$ and $C_{\text {size, } 0}$ are the concentrations of particles of a given size at times $t$ and 0 , respectively. For all measurements, a check was made to confirm that the decline in $\ln C$ was linear over time (i.e. confirm assumption of constant pumping rate). $\mathrm{RE}_{\text {size, } t}$ values were standardized across the full range of particle sizes measured by setting the highest $\mathrm{RE}_{\text {size }}$ to 1 (designated as $\mathrm{RE}_{\max }$ ) and proportionately adjusting $\mathrm{RE}_{\text {size }}$ for the other particle size bins (Møhlenberg \& Riisgård 1978). Standardized $\mathrm{RE}_{\text {size }}$ values are reported below as $\mathrm{RE}_{\text {std. }}$ RE values obtained by Eq. (1) represent the cumulative particle capture response of the suspension feeder(s) in the chamber over an elapsed time ranging from $30 \mathrm{~s}$ to $30 \mathrm{~min}$. RE was measured over a range of elapsed times to determine if the standardized RE for each particle suspension was dependent on feeding time.

The precision of values obtained using Eq. (1) is related to the variability in particle counts measured during just 2 sampling times (start and end). To increase measurement precision and to better assess the quality of RE measurements, the exponential decay of particles in feeding chambers was analyzed 
using an approach that utilizes all the time-series data simultaneously to provide a single $\mathrm{RE}_{\text {size }}$ value for each diet treatment. Particle depletion in a static chamber is represented as a continuous function that follows (from Coughlan 1969):

$$
\frac{\mathrm{d} C}{\mathrm{~d} t}=-\lambda C
$$

where $C$ is the concentration of particles and $\lambda$ is the exponential decay constant, which in turn is a function of $\mathrm{PR}, \mathrm{RE}$ and the chamber volume $(V)$. Given the dependence of RE on particle size, $\lambda$ is size-specific:

$$
\lambda_{\text {size }}=\lambda_{\text {size }}\left(\mathrm{PR}, \mathrm{RE}_{\text {size }}, V\right)
$$

Given that PR and $V$ are assumed to be constant during the feeding trials and independent of particle size, $\lambda_{\text {size }}$ can be used as an indicator to compare RE among particles of different size. Therefore, Eq. (2) can be integrated for each particle size:

$$
C_{\text {size }, t}=C_{\text {size }, 0} \times \mathrm{e}^{-\lambda} \text { size }^{t}
$$

Applying logarithms:

$$
\ln C_{\text {size }, t}-\ln C_{\text {size }, 0}=-\lambda_{\text {size }} t
$$

This linear form of the equation was applied to the time-series data collected with the PAMAS for each particle size, and $\lambda_{\text {size }}$ was calculated as the slope of the linear regression between $\ln C_{\text {size }}$ and the elapsed time. It was assumed that the maximum $\lambda_{\text {size }}$ corresponds to particles that can be effectively retained (i.e. $100 \%$ after standardization). Accordingly, the following relationship was used to standardize RE for each particle size:

$$
\mathrm{RE}_{\text {size }}=\frac{\lambda_{\text {size }}}{\lambda_{\max }}
$$

where $\lambda_{\max }$ is the maximum $\lambda_{\text {size }}$ obtained in Eq. (5). This results in a RE scale ranging from 0 to 1 , representing particle sizes that are not retained and retained at maximum efficiency, respectively. The $\mathrm{r}^{2}$ of the regression between $\ln C_{\text {size }}$ and elapsed time was used as a standardized means of assessing the effect of temporal variability in (1) particle counts on these measurements and (2) pumping rate of bivalves. To minimize the effect of this analytical error or behavioural change, regressions with $\mathrm{r}^{2}$ below 0.95 were considered to represent a condition where the $\mathrm{RE}_{\text {size }}$ value obtained was of low precision because of excessive variability in particle counts between sampling times or changes in pumping behaviour. Setting such a high $\mathrm{r}^{2}$ threshold represents an extremely conservative approach (i.e. statistically robust) to ensur- ing the high precision of RE values calculated by this method. Residuals were also visually analyzed to discard bias across elapsed time.

Flow-through method

The flow-through method for measuring particle $\mathrm{CR}$ and $\mathrm{RE}$ is intended to simulate more natural conditions experienced by sessile suspension feeders than the static method. The feeding chambers employed were the same as described by Strohmeier et al. $(2009,2012)$. In brief, the internal dimensions of the chambers were $3.8 \mathrm{~cm}$ wide, $19.5 \mathrm{~cm}$ long and $8.1 \mathrm{~cm}$ high, with an internal design that constrains recirculation of water past the suspension feeders when an acceptable flow speed is provided. RE was measured for mussels exposed to the natural seston using 40 separate flow-through chambers. Four additional chambers were left empty to control for any effect the chamber may have on the outflow particle concentration. The seawater supply to all chambers was pumped from $7 \mathrm{~m}$ depth (15 $\mathrm{m}$ total depth at seawater inlet) into a header tank. The flow rate to each chamber from the header tank was controlled by individual valves, and the flow rate exiting each chamber was measured at the chamber outlets immediately before beginning any measurements. The bivalves were left undisturbed in chambers with flowing seawater at least $1 \mathrm{~h}$ to resume feeding before sampling water from the outlet of the chambers. Water samples collected from each chamber outlet were analyzed for particle concentration and size distribution using the PAMAS particle analyzer. Three $10 \mathrm{ml}$ subsamples from each water sample were analyzed using the PAMAS, and mean particle counts for each suspension feeder were used to calculate size-specific RE (32 particle size channels) according to:

$$
\mathrm{RE}_{\text {size }}=1-\left(C_{\mathrm{e}} / C_{\mathrm{c}}\right)
$$

where $C_{\mathrm{c}}$ is the particle count exiting the control chamber and $C_{\mathrm{e}}$ is the count in water exiting the suspension feeder chamber. CRs were calculated as the product of the flow rate to the chamber and the RE of particles averaged over the 3.75 to $7.75 \mu \mathrm{m}$ size range. Suitable flow rates for the chambers were previously identified by Strohmeier et al. (2009; 11141 $\mathrm{h}^{-1}$ for mussels of similar size as used in the present study) to ensure that measured CRs are flow independent. However, additional tests were conducted to further investigate the possibility of flow effects on RE. For this assessment, 80 measurements were conducted with mussels using flow rates between 1 and 
$501 \mathrm{~h}^{-1}$. All RE measurements were standardized as for the static method; $\mathrm{RE}_{\text {size }}$ was expressed as a fraction of $\mathrm{RE}_{\max }$.

\section{Statistical analysis}

Curve fitting and regression analysis were performed with SigmaPlot Version 12 (Systat Software). One-way ANOVA comparisons were performed at $\alpha=$ 0.05 with Systat Version 13 software (SPSS). Prior to hypothesis testing, the data were screened for normality and homoscedasticity by examining normal probability and residual plots (Wilkinson et al. 1996).

\section{RESULTS}

\section{Characterization of experimental particle suspensions}

Average particle size distributions for the natural seston and seston/clay mixtures are shown in Fig. 1. The seston from $7 \mathrm{~m}$ depth at the study site consisted primarily of particles smaller than $16 \mu \mathrm{m}$, with a steady logarithmic decline in particle counts across the size spectra (Fig. 1a). The volume concentration peaked at approximately $5 \mu \mathrm{m}$ and rapidly declined for particles larger than $11 \mu \mathrm{m}$ (Fig. 1b). Addition of the stock clay to the unfiltered seawater (reference suspension) resulted in a uniform increase in particle counts for all size bins, with counts increasing by an average of $35 \%$ (Fig. 1a). The clay additions had little effect on the shape of the seston volume distribution (Fig. 1b). Particle counts in the algal cell diet treatments were between 7 and 12 times higher than for the natural seston diets. The median size (ESD) of the 5 microalgal species measured with the PAMAS was similar to median cell lengths obtained by microscopy (difference in median size averaged $1.0 \pm 1.1 \mu \mathrm{m}$ SD).

\section{RE based on the static method}

Water temperature and salinity during the study period were $12.7 \pm 0.5^{\circ} \mathrm{C}$ (mean $\pm \mathrm{SD}$ ) and $27.2 \pm 1.6$, respectively. $\mathrm{RE}$ size distributions of mussels feeding on natural seston are shown in Fig. 2. The standardized $\mathrm{RE}$ results $\left(\mathrm{RE}_{\mathrm{std}}\right)$ based on Eq. (1) were calculated for 5 sampling intervals ranging from 1 to $16 \mathrm{~min}$. The longest time span was chosen after preliminary observations showed that the decline in $\ln C$ remained linear for this period. The standardization of these data assumed that maximum RE occurred within the size range 1.25 to $11.25 \mu \mathrm{m}$. The reason for deciding on this range is described below. Although the shape of the $\mathrm{RE}_{\text {std }}$ size distribution was generally similar regardless of the time between initial and final samples, RE increased for most particle sizes with increasing elapsed time (Fig. 2a). Short sampling intervals $(<2 \mathrm{~min})$ resulted in relatively low $\mathrm{RE}$ across the size spectra and higher variability compared with longer intervals (Fig. 2a). Longer sampling intervals tended to reduce the measured $\mathrm{RE}_{\max }$ and an elapsed time of 16 min indicated maximum retention for particles larger than approximately 8 to $9 \mu \mathrm{m}$. RE decreased gradually below this threshold to an average of $42 \%$ for the $2.25 \mu \mathrm{m}$ size bin (Fig. 2a). The average RE for 3 to $4 \mu \mathrm{m}$ particles was approximately $60 \%$.
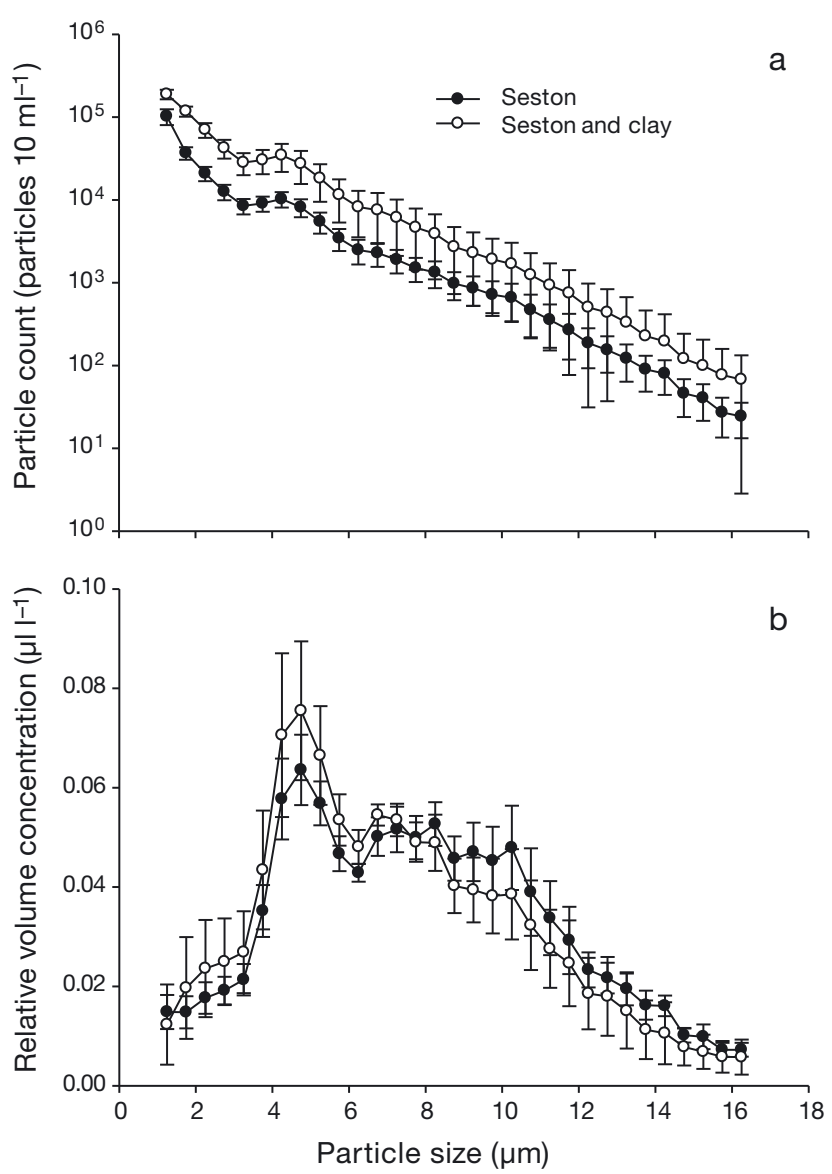

Fig. 1. Particle size distributions of the natural seston (closed circles) and seston/clay mixture (open circles) used in feeding experiments with mussels and tunicates. Size distributions are provided based on (a) particle numbers per $10 \mathrm{ml}$ sample and (b) volume concentrations relative to the total particle volume in suspension $\left(\mu l^{-1}\right)$. Mean $( \pm \mathrm{SD} ; \mathrm{n}=5)$ values are shown for each particle suspension sampled from static chambers at the start of feeding experiments 

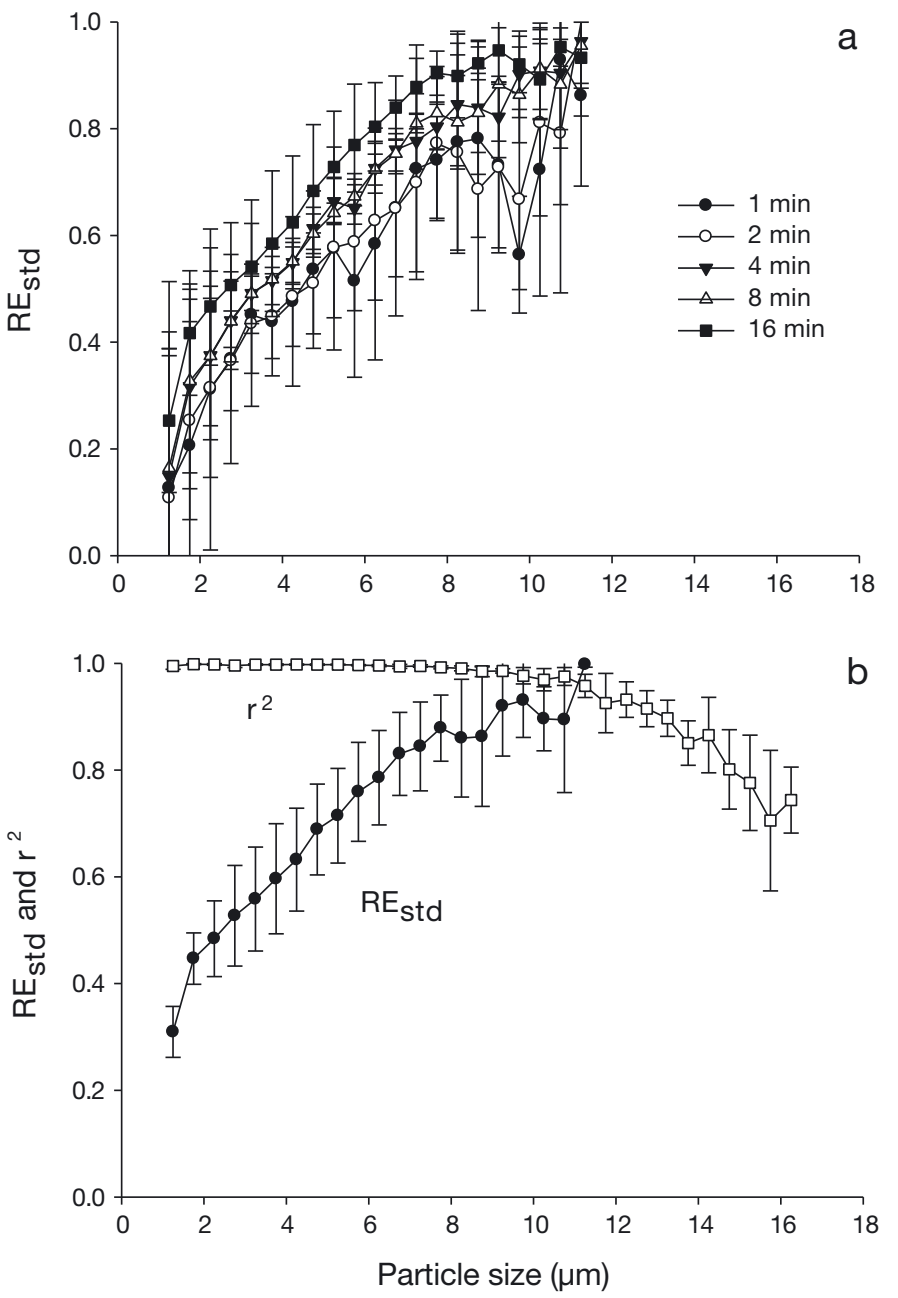

Fig. 2. Standardized retention efficiency $\left(\mathrm{RE}_{\text {stdi }}\right.$ mean $\pm \mathrm{SD}$; $\mathrm{n}=5$ ) of natural seston particles by Mytilus edulis as measured by the static method using (a) traditional data analysis (Eq. 1 in text based on 5 standard elapsed times: 1, 2, 4, 8 and $16 \mathrm{~min}$ ) and (b) time-series regression method (Eq. 6 in text), showing $\mathrm{r}^{2}$ values; only $\mathrm{RE}_{\text {std }}$ values with an associated $r^{2} \geq 0.95$ are displayed to control for errors from excessive variability in particle counts

Unlike the traditional approach to calculating RE from the static method (Eq. 1), RE results obtained using Eq. (6) (referred to hereafter as the regression method) utilized all the time-series data (30 s sampling intervals over a total period of $15 \mathrm{~min}$ ) to characterize the retention of particles in each size bin. Mean results obtained using this method showed a similar relationship between $\mathrm{RE}$ and particle size (Fig. 2b) as observed for the traditional method with a 16 min sampling interval (Fig. 2a), albeit with lower variability. The results of regression analysis of the relationship between $\ln C_{\text {size }}$ and sampling time are also shown in this figure, and the $\mathrm{r}^{2}$ value declined below 0.95 for particles larger than $11.25 \mu \mathrm{m}$. The relatively high variability of particle counts in larger size bins decreased the curve fit to a level where the precision of $\mathrm{RE}_{\mathrm{std}}$ results was too heavily influenced by temporal variability in the relatively low particle counts to provide precise results. For this reason, all RE measurements reported for the seston diet were limited to the 1.25 to $11.25 \mu \mathrm{m}$ size range (Fig. 2).

Mussels exposed to the reference particle suspension, containing a mixture of natural seston and clay particles, exhibited similar $\mathrm{RE}_{\text {std }}$ spectra (Fig. 3) as described in this subsection for the pure seston suspension (Fig. 2). As with the seston diet, the results obtained using Eq. (1) show that $\mathrm{RE}_{\text {std }}$ progressively increased for most particle sizes as the elapsed time in the chamber increased (Fig. 3a). The regression method identified the size range between 2.25 and $11.25 \mu \mathrm{m}$ as providing precise values for this particle suspension $\left(r^{2} \geq 0.95\right)$, and $R E_{\text {std }}$ declined steadily below a mean $\mathrm{RE}_{\text {max }}$ at $11.25 \mu \mathrm{m}$ (Fig. 3b). Curves describing an exponential rise to a maximum were fit to mussel $\mathrm{RE}_{\text {std }}$ data for each particle suspension and provided the following equations:

Seston (Fig. 2b):

$$
\begin{aligned}
& \mathrm{RE}_{\text {std }}=1.067( \pm 0.048)\left\{1-\mathrm{e}^{[-0.227( \pm 0.025) \times \text { Size }]}\right\} \\
& \mathrm{r}^{2}=0.985, \mathrm{p}<0.0001
\end{aligned}
$$

Reference (Fig. 3b):

$$
\begin{aligned}
& \mathrm{RE}_{\text {std }}=1.145( \pm 0.050)\left\{1-\mathrm{e}^{[-0.197( \pm 0.019) \times \text { Size }]}\right\} \\
& \mathrm{r}^{2}=0.987, \mathrm{p}<0.0001
\end{aligned}
$$

where values in parentheses are the $95 \%$ CI for each coefficient. Despite the close fit of these data to the regression model, coefficient CIs overlapped for both diets, indicating that the addition of clay to natural seston had no apparent effect on the size-specific $\mathrm{RE}_{\text {std }}$ response of mussels. The retention of the 5 algal cell suspensions by mussels (Fig. 4), calculated using the regression method, followed a similar relationship with particle size as for the seston (Fig. 2) and reference diets (Fig. 3).

The $\mathrm{RE}_{\text {std }}$ responses of Ciona intestinalis, averaged for both the seston and reference diets, are shown in Fig. 5. As with the mussels, the traditional calculation approach gave markedly different results depending on the length of the sampling interval (Fig. 5a). The regression approach indicated that measurement precision was high for particle sizes between 1.25 and $11.25 \mu \mathrm{m}$ and that over $95 \%$ of particles larger than approximately $5 \mu \mathrm{m}$ were retained (Fig. 5b). RE $E_{\text {std }}$ declined below this size to an average of $71 \%$ retention for $1.25 \mu \mathrm{m}$ particles. The following equation described the relationship between $R E_{\text {std }}$ and particle size for this species: 

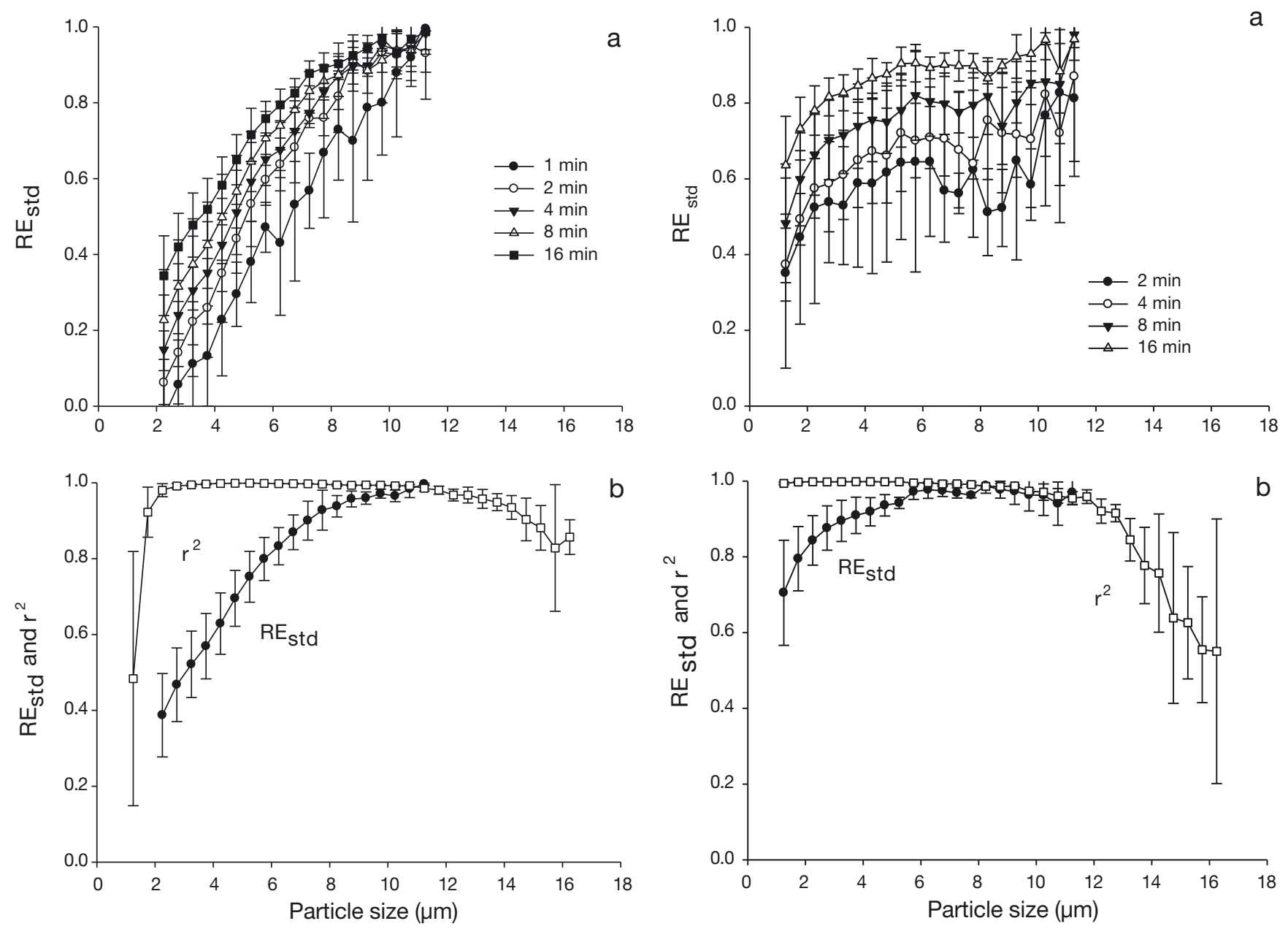

Fig. 3. Same as Fig. 2 except that the standardized retention efficiency $\left(\mathrm{RE}_{\text {stdi }}\right.$ mean $\left.\pm \mathrm{SD} \mathrm{n}=4\right)$ of mussels is for a diet that consisted of a mixed suspension of seston and clay particles

Fig. 5. Same as Fig. 2 except that standardized retention efficiency $\left(\mathrm{RE}_{\text {stdi }}\right.$ mean $\pm \mathrm{SE} ; \mathrm{n}=3$ ) is for tunicates Ciona intestinalis exposed to natural seston $(\mathrm{n}=1)$ and mixtures of seston and clay particles $(n=2)$

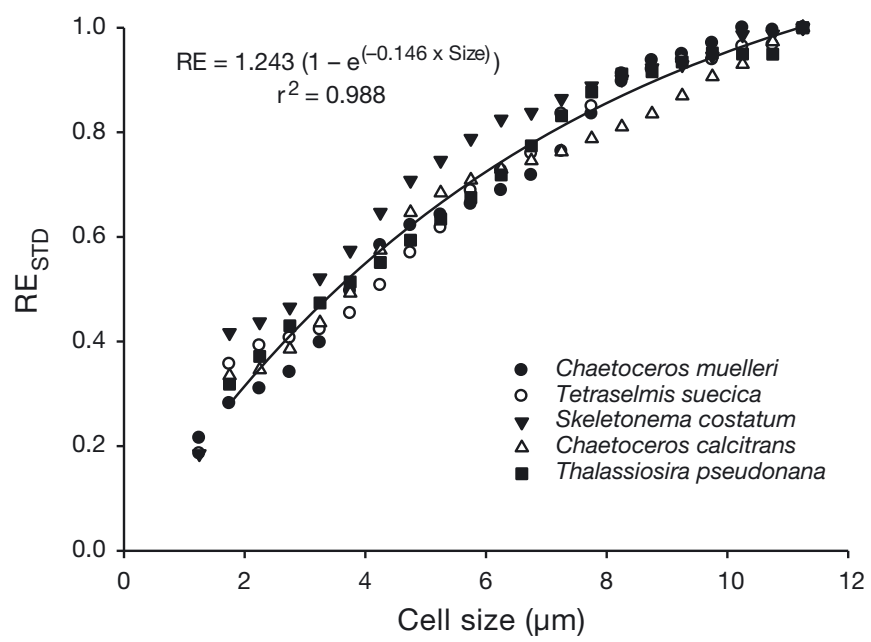

Fig. 4. Standardized retention efficiency $\left(\mathrm{RE}_{\mathrm{std}}\right)$ of algal cell cultures by Mytilus edulis measured using the static chamber method and time-series regression analysis (Eq. 6 in text)

$$
\begin{aligned}
& \mathrm{RE}_{\text {std }}=0.961( \pm 0.010)\left\{1-\mathrm{e}^{[-0.970( \pm 0.075) \times \text { Size }]}\right\} ; \\
& \mathrm{r}^{2}=0.937, \mathrm{p}<0.0001
\end{aligned}
$$

Comparison of Eqs. (8-10) (and Figs. 2-5) shows that the tunicates retained a larger fraction of all particle sizes below approximately $8 \mu \mathrm{m}$ than the mussels.

\section{RE based on flow-through method}

Mussel RE values averaged across the 3.75 to $7.75 \mu \mathrm{m}$ size range of seston particles (selected based on traditional assumptions regarding maximum RE) declined exponentially with increasing flow speed (decreasing water residence time) in the feeding chambers (Fig. 6). Although this range of flows and $\mathrm{RE}$ values can occur under natural conditions, $\mathrm{CR}$ measurements obtained with this method are only 


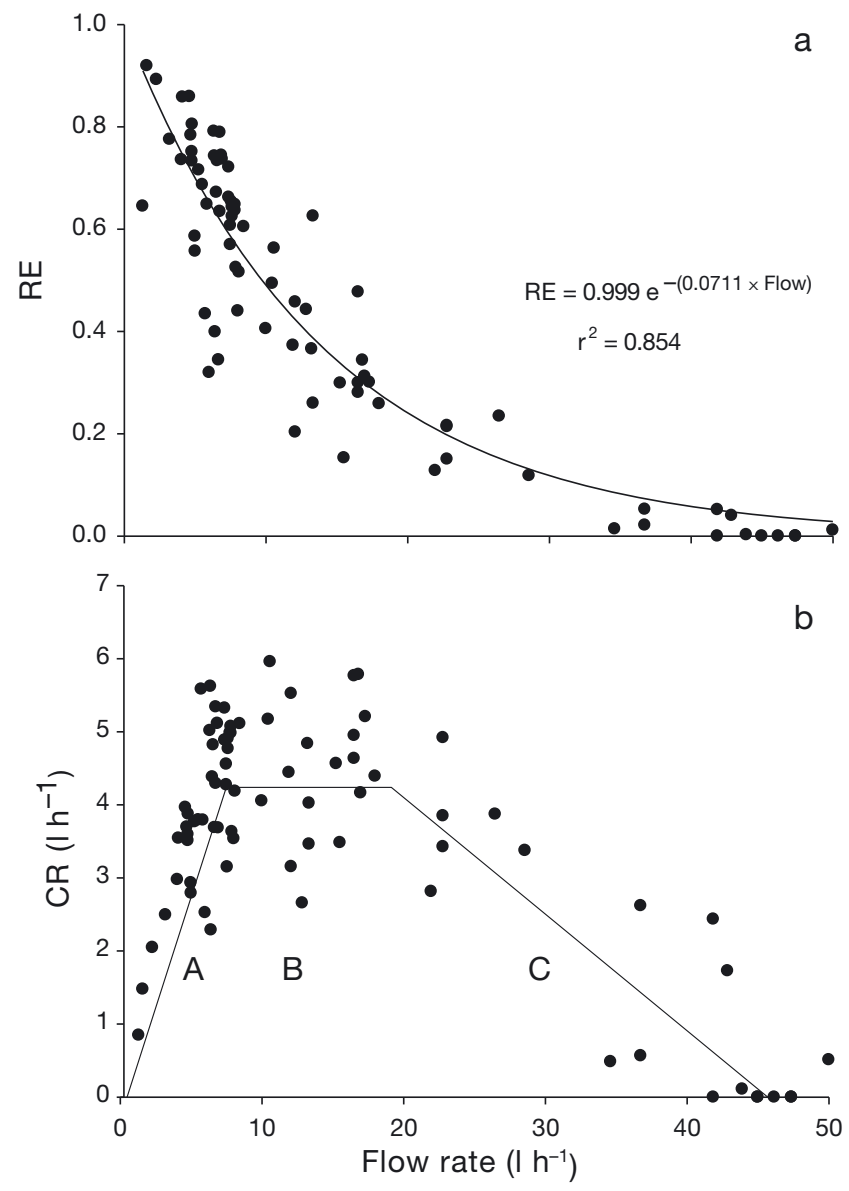

Fig. 6. Relationships between the flow rate to feeding chambers (flow-through method) and the (a) unstandardized retention efficiency (RE) and (b) clearance rate (CR) of natural seston by Mytilus edulis. The labels and lines (drawn by eye) on the CR plot indicate (A) flow dependency, (B) flow independency and $(C)$ feeding inhibition phases

considered to be accurate when independent of flow rate. Individual mussel CRs, calculated from RE values measured at the different flows, were observed to be dependent on flow at relatively low and high speeds (Fig. 5). The CR data were grouped over 7 flow ranges ( 0 to 5,5 to $7.5,7.5$ to 10,10 to 15,15 to 20,20 to 25 and 25 to $30 \mathrm{l} \mathrm{h}^{-1}$ ), and normal probability plots showed that a normal distribution was present only for the 3 groups with flow rates between 7.5 and $20 \mathrm{l} \mathrm{h}^{-1}$. Skewed distributions and heteroscedasticity of $\mathrm{CR}$ data were detected for the remaining flow ranges (Fig. 5). One-way ANOVA showed no significant difference in mean $\mathrm{CR}$ values measured for the 7.5 to 10,10 to 15 and 15 to $20 \mathrm{l} \mathrm{h}^{-1}$ flow ranges $(\mathrm{df}=28, F$-ratio $=0.748, \mathrm{p}=0.483)$. This flowindependent range provided an average $\mathrm{CR}$ of $4.5 \mathrm{l}$ $\mathrm{h}^{-1}(\mathrm{SD}=0.8)$ for mussels averaging $54.8 \mathrm{~mm}(\mathrm{SD}=$ 1.3) shell length.

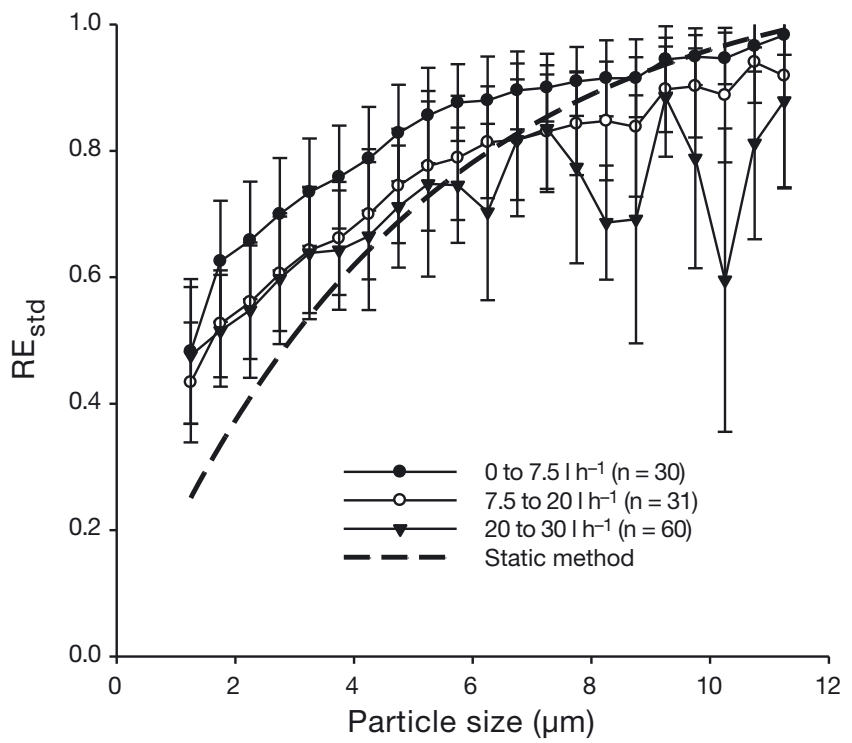

Fig. 7. Mean (SD) standardized retention efficiency ( $\left.\mathrm{RE}_{\mathrm{std}}\right)$ of natural seston particles by Mytilus edulis measured by the flow-through method using the indicated flow rate ranges. The broken line summarizes $\mathrm{RE}_{\text {std }}$ data obtained with the time-series static method (Eq. 8 in text). Sample size (n) is shown for each flow rate range

The effect of flow rate on the $\mathrm{RE}_{\text {std }}$ size distribution is shown in Fig. 6. These calculations assume that the $\mathrm{RE}_{\max }$ for the seston suspension occurred within the same size range as identified for the static method $(1.25$ to $11.25 \mu \mathrm{m})$. As with the static method, the shape of the $R E_{\text {std }}$ size distribution varied with the time the mussels had to clear particles passing through the chamber (i.e. residence time). Highest residence times occur during the flow dependency phase $\left(0\right.$ to $\left.7.51 \mathrm{~h}^{-1}\right)$ and resulted in relatively high retention of all particle sizes below the $\mathrm{RE}_{\max }$ (Fig. 6). Reducing residence time resulted in a reduction in the efficiency of mussels to retain the majority of available seston particles (Figs. 1 \& 7). The increased variability in $\mathrm{RE}_{\text {std }}$ during the flow inhibition phase $\left(>20 \mathrm{l} \mathrm{h}^{-1}\right)$ reflected the relatively small difference in particle concentrations between the control and mussel chambers. At these high flows, the effect of mussel feeding on seston concentration was approaching the range of variability in seston concentrations in control chambers.

Eq. (8) was also plotted in Fig. 7 for comparison of $\mathrm{RE}_{\text {std }}$ results obtained for natural seston using both the flow-through and static chamber methods. Both approaches showed a gradual decline in $\mathrm{RE}_{\text {std }}$ below an $\mathrm{RE}_{\max }$ within the 9 to $11.25 \mu \mathrm{m}$ size bins. However, the static method indicated a slightly faster decline in $\mathrm{RE}_{\text {std }}$ with reducing particle size and a lower reten- 
tion of particles smaller than $4 \mu \mathrm{m}$ (Fig. 7). However, even for these small particle sizes, there was considerable overlay in RE results obtained using both methods (Figs. $2 \& 7$ ).

\section{DISCUSSION}

Blue mussels Mytilus edulis in Lysefjord, Norway, displayed maximum RE for particles larger than 8 to $11 \mu \mathrm{m}$. The retention of smaller particles declined slowly, with 50 to $60 \%$ retention of $4 \mu \mathrm{m}$ particles and 30 to $40 \%$ retention of $2 \mu \mathrm{m}$ particles. This RE size distribution was maintained for mussels fed natural seston, mixtures of seston and clay, and algal cell monocultures. These observations indicate that the established relationship between RE and particle size for this species (see 'Introduction') does not consistently apply across the broad biogeographic distribution of this species. The CRs of mussels, which averaged $4.5 \mathrm{l} \mathrm{h}^{-1}$ for the flow-independent phase, were measured using the commonly accepted approach of assuming $100 \% \mathrm{RE}$ for particles larger than approximately $4 \mu \mathrm{m}$ (Cranford et al. 2011). Rather than being completely retained, $4 \mu \mathrm{m}$ particles were actually retained at 61 to $86 \%$ efficiency, indicating an incorrect use of the indirect method (Williams 1982). Recalculation based on the measured depletion of particles in the 8.25 to $11.25 \mu \mathrm{m}$ size range yielded a $20 \%$ increase in average CR $\left(5.61 \mathrm{~h}^{-1} ; \mathrm{SD}=\right.$ 1.5). It is therefore recommended that the RE size distribution be routinely determined to identify the size range of effectively retained particles prior to calculating bivalve CRs with the indirect method.

The present study investigated possible sources of error in 2 basic approaches for estimating RE (static and flow-through methods) with the purpose of validating their performance in studies with natural seston and to recommend any methodological improvements. The RE size distribution measured using the static method was shown to be dependent on the selected sampling interval. RE data obtained using the static method showed that the retention of most particle sizes increased with the time the mussels and tunicates were exposed to the particle suspension. This apparent time dependency in RE is not indicative of a biological response but reflects accumulated mathematical errors related to variability in the concentration decay and the apparent size of maximum particle retention $\left(\mathrm{RE}_{\max }\right)$. Both parameters are more precisely determined as the difference between $C_{0}$ and $C_{t}$ increases with time. Given that standardization of individual measurements is based on $\mathrm{RE}_{\max }$, values obtained after a relatively long exposure time (16 min in the present study) should provide the most reliable measure of the true RE size distribution. The decline in $\ln C$ remained linear over this time period in the current study, but this requirement should be checked prior to any calculations of RE by the static method. A consequence of this requirement is that the static method is unsuitable for measuring rapid fluctuations in particle capture rates and efficiencies.

The availability of automated particle counting instrumentation facilitates a more statistically robust approach for measuring RE and CRs using the static method. The regression approach developed in the current study utilized an average of 30 sampling periods to calculate the RE of particles in each of 32 size bins over short (30 s) sampling intervals. This large sample size facilitates the high precision of measurements, while setting an $\mathrm{r}^{2}$ threshold at 0.95 ensures that only accurate results are presented. A regression approach has been used previously to ensure the linear decay of particle concentrations in static chambers (Bayne et al. 1999) and to calculate CRs (Riisgård \& Seerup 2003). However, the automated high-frequency sampling and particle analysis approach reported herein, combined with Eq. (6), represents a novel method for estimating RE that ensures a high degree of measurement accuracy and statistical precision.

Standardized RE results based on the modified static method were generally similar to those obtained with the flow-through method. The $\mathrm{RE}_{\max }$ occurred within the same 8 to $11 \mu \mathrm{m}$ size range, and retention declined to approximately $60 \%$ for $4 \mu \mathrm{m}$ particles. Some variation in the $\mathrm{RE}_{\text {std }}$ spectrum was observed to occur for the different flow rates, with relatively high RE measured at low flows $\left(<7.5 \mathrm{l} \mathrm{h}^{-1}\right)$ and highly variable efficiencies measured at high flows (>20 $\mathrm{l} \mathrm{h}^{-1}$; Fig. 6). The flow-through method is known to provide flow-dependent feeding rate responses because of flow bypass and/or inhibition of the bivalve pump at high flows and recirculation at low flows (e.g. Filgueira et al. 2006). Consequently, $\mathrm{CR}$ and RE results obtained using this method are only reliable for the flow independency phase, which was between 7.5 and $20 \mathrm{l} \mathrm{h}^{-1}$ (Fig. 6) for the chamber geometry employed in the current study. Recirculation at low flows will result in the flow-through chamber behaving more like a static chamber, in which particles are depleted exponentially during the residence time of water in the chamber. The assumed linear difference in particle concentrations exiting the control and experimental chambers (Eq. 7) is 
therefore not valid for low flows, resulting in erroneous RE measurements. The high variability in RE values measured at high flows resulted, at least in part, from the magnitude of particle removal by the suspension feeder approaching the analytical error for estimating particle concentrations.

Rosa et al. (2015) reported that $4 \mu \mathrm{m}$ and larger polystyrene beads were retained with maximum efficiency by mussels and suggested that lower RE values, such as reported herein for particles $\geq 4 \mu \mathrm{m}$, are the result of methodological errors related to several potentially confounding factors (see 'Introduction'). These results are in contrast to those of Dunphy et al. (2006), who showed that oysters retained $6 \mu \mathrm{m}$ polystyrene beads at a significantly lower efficiency than $15 \mu \mathrm{m}$ beads. Oysters have been reported to exhibit a similar RE size spectra as mussels (Møhlenberg \& Riisgård 1978). The present study used a natural particle source, with uniform physical properties across the particle size distribution, to control for possible sources of error in RE measurements caused by variations in particle shape and surface properties. The use of polystyrene beads was considered less suitable as a reference suspension for the following reasons. First, the reference particles should ideally include a continuous particle size distribution that mimics the seston under study and which can be added to the seston for simultaneous particle analysis using the same instrumentation. Mathematical artifacts may arise if RE responses to reference and experimental particles are measured and/or standardized separately. Second, polystyrene microspheres are inherently hydrophobic and strongly attract each other. A surface charge, added during their synthesis, and/or the use of a surfactant is required to facilitate their dispersion in aqueous media. Although Rosa et al. (2013) showed that the surface charge of the fluorescent beads employed was similar to other marine particles, this charge is insufficient for colloidal stability, and a surfactant is employed to maintain particle dispersion. Addition of dispersed beads to seawater in feeding chambers or directly into the inhalant siphon dilutes the surfactant, and the hydrophobic beads regain a high affinity for attraction/ aggregation and attachment to surfaces, including bivalve feeding structures. In addition, surfactants of the type employed to ensure microsphere dispersion are known to inhibit the CRs of $M$. edulis (Ostroumov \& Widdows 2006) and may result in an artificial feeding response.

The present study employed a glaciomarine clay to serve as a reference diet. The particle size distribution of the clay was very similar to that of the seston at the study site (Fig. 1). Previous particle aggregation tests with this same clay source resulted in no flocs being formed even after $1 \mathrm{wk}$ in a flocculator (Milligan 1996). Although this same source of clay will flocculate at relatively high concentrations under static conditions, concentrations below $30 \mathrm{mg} \mathrm{l}^{-1}$ did not begin to form flocs for several hours (Kranck 1980). The aggregation of clay particles during the relatively short period within feeding chambers was therefore expected to be minimal. Previous comparisons of average CR responses of $M$. edulis to seston particles and mixed suspensions of seston and natural marine inorganic matter showed no significant differences (Bayne et al. 1987). However, CRs may be expected to decline at clay concentrations greater than employed in the present study (Widdows et al. 1979). Average RE size distributions measured for mussels exposed to both the seston and reference (seston/clay mixture) suspensions were very similar, and the regression equation coefficients describing the RE responses to these 2 treatments were within $95 \%$ CIs. It was therefore concluded that the reported RE responses of mussels to the natural seston particles available during this study are not caused by artifacts from confounding physical attributes of constituent particles but accurately reflect the response of mussels under the conditions at the study site. However, particle shape effects on RE cannot always be discounted. Under conditions where the seston is dominated by lengthy phytoplankton cells or detritus, the variable orientation of these particles as they pass the instrument detector will result in estimates of particle sizes that do not adequately reflect their capacity to be retained by a suspension feeder.

The comparison of RE responses by M. edulis and Ciona intestinalis provides further evidence of the accuracy of the reported measurements. As noted in the 'Introduction', possible methodological artifacts that could potentially give an erroneous impression of an individual's RE spectrum should consistently arise regardless of the suspension feeder being studied. However, the tunicates were observed to have a markedly different RE spectrum (Fig. 5) than mussels and retained $>70 \%$ of particles larger than $1 \mu \mathrm{m}$. The $\mathrm{RE}$ spectra of $C$. intestinalis has been reported previously based on laboratory studies with diets consisting of marine flagellates (Randløv \& Riisgård 1979), algal cell cultures and bacterioplankton (Jørgensen et al. 1984). The present study with natural seston confirms the conclusion from those studies that filtration through the tunicate mucus net consistently results in the effective retention of particles as small 
as 1 to $2 \mu \mathrm{m}$. The filtration mechanism of mussels is considerably more complex, and the exact mechanisms of particle capture are still controversial (reviewed in Ward et al. 1998). Numerous factors, in addition to particle size, have been shown to strongly influence particle capture without any methodological explanation (reviewed by Ward \& Shumway 2004). The capture of particles takes place upstream of a current produced by the beating of lateral cilia/ cirri on the ctenidial filaments. The laterofrontal cilia/cirri have been proposed to act as mechanical sieves, such that particle RE is somewhat correlated with the degree of development of these structures (Jørgensen et al. 1984, Riisgård 1988, Silverman et al. 1996). However, Ward et al. (1998) suggested that this particle impaction mechanism is not possible at the applicable Reynolds numbers. These authors proposed a hydrosol filtration theory in which particles are captured on the ctenidial filaments through direct interception with the frontal ciliary tracts. They suggest that interspecific differences in particle RE are associated with the flow patterns that are produced by the type of laterofrontal cilia/cirri present. They also proposed that an individual bivalve might adjust feeding rate and efficiency by altering the amount of water passing directly through the interfilamentary spaces through the regulation of vortical flow patterns set up by the beating of the laterofrontal cirri. A mechanical sieving mechanism is not compatible with our observations of a slow decline in $\mathrm{RE}$ below the size of maximum retention. In addition, previous observations of a seasonally variable RE size distribution (Strohmeier et al. 2012, Rosa et al. 2015) lend support to the theory of a hydrosol filtration mechanism in bivalves, as described by Ward et al. (1998).

Strohmeier et al. (2012) reported that relatively small particles were occasionally captured more effectively than larger ones. The present study examined the precision of RE measurements across the ambient particle size spectra and showed that the high variability of particle concentrations in size bins larger than $11.2 \mu \mathrm{m}$ consistently reduced the precision of RE values for those sizes. Measurements obtained for relatively large particle sizes were shown to be of low reliability and are not reported (Figs. 2-5 \& 7). However, measurement precision is not strictly a function of particle size but will depend on regional and seasonal variations in seston concentrations. It is therefore not possible, based on the results of the current study, to preclude the possibility of reduced $\mathrm{RE}$ of relatively large particles.

\section{CONCLUSIONS}

The results of the present study showed that the RE size distribution of mussels feeding on natural seston does not always conform to the traditionally assumed model. This result, which was confirmed using $3 \mathrm{RE}$ methodologies and 3 types of particle suspensions, cannot be attributed to potential methodological artifacts. Both the static and flow-through methods provided comparable results when the inherent assumptions were verified. Selection of an appropriate sampling interval is critical to providing accurate results with the static method, while the proper use of the flow-through method requires that feeding behaviour and particle availability in feeding chambers is not flow dependent, as has previously been reported. Standardization of RE data can be problematic for all methods given that mathematical errors will result from inaccurately identifying the particle size at which $R E$ is most efficient $\left(R E_{\max }\right)$. A new approach - based on the static method - is described, that provides a statistical analysis of the reliability of all results. This time-series regression approach overcomes the problem of time dependency in previous measurements and provides a more rigorous means of identifying $\mathrm{RE}_{\text {max }}$. Results obtained using this new approach show that the reliability of RE measurements is greatly reduced when the ambient particle concentration is low.

The previous assumption of an unchanging RE size spectrum for each bivalve species has contributed to numerous conclusions on bivalve trophic resources and food partitioning between species, as well as on the ecological services and environmental effects of the biofiltration activities of bivalve populations. Rather than continuing to assume $100 \%$ RE for all particles larger than $4 \mu \mathrm{m}$, as a prerequisite for measuring mussel CRs with the indirect method, it is first necessary to confirm the size range of effective retention. Extrapolation of individual CRs to dense populations of wild and cultured bivalves will greatly compound any methodological error. While the focus of this study was on mussels, any suspension feeder that filters particles by means other than mechanical sieving may exhibit similar variability in the size distribution of particles retained by the feeding apparatus.

Acknowledgements. The work was carried out as part of 2 projects funded by the Research Council of Norway: 'Tracing phytoplankton grazed by mussels using molecular methods to identify preys and improve modeling' (TRAPH; Project No. 225213) and 'Carrying capacity of native low- 
trophic resources for fish feed ingredients - the potential of tunicate and mussel farming' (CARLO; Project No. 234128). We thank Sissel Andersen, Cathinka Krogness and Henrice Jansen for providing cultured algal cells and Samuel Rastrick for support and facilities at the study site. We also thank Evan Ward and Maria Rosa for valuable discussions during the preliminary design of this study.

\section{LITERATURE CITED}

Barillé L, Prou J, Heral M, Bourgrier S (1993) No influence of food quality, but ration-dependent retention efficiencies in the Japanese oyster Crassostrea gigas. J Exp Mar Biol Ecol 171:91-106

Bayne BL, Hawkins AJS, Navarro E (1987) Feeding and digestion by the mussel Mytilus edulis L (Bivalvia: Mollusca) in mixtures of silt and algal cells at low concentrations. J Exp Mar Biol Ecol 111:1-22

Bayne BL, Svensson S, Nell JA (1999) The physiological basis for faster growth in the Sydney rock oyster, Saccostrea commercialis. Biol Bull 197:377-387

Coughlan J (1969) The estimation of filtration rate from the clearance of suspensions. Mar Biol 2:356-358

Cranford PJ, Ward JE, Shumway SE (2011) Bivalve filter feeding: variability and limits of the aquaculture biofilter. In: Shumway SE (ed) Shellfish aquaculture and the environment. Wiley-Blackwell, Chichester, p 81-124

Dunphy BJ, Hall JA, Jeffs AG, Wells RMG (2006) Selective particle feeding by the Chilean oyster, Ostrea chilensis implications for nursery culture and broodstock conditioning. Aquaculture 261:594-602

Filgueira R, Labarta U, Fernandez-Reiriz MJ (2006) Flowthrough chamber method for clearance rate measurements in bivalves: design and validation of individual chambers and mesocosm. Limnol Oceanogr Methods 4: 284-292

Haven DS, Morales Alamo R (1970) Filtration of particles from suspension by the American oyster Crassostrea virginica. Biol Bull 139:248-264

Jørgensen CB (1974) On gill function in the mussel Mytilus edulis L. Ophelia 13:187-232

Jørgensen CB, Kiørboe T, Møhlenberg F, Riisgård HU (1984) Ciliary and mucus-net filter feeding, with special reference to fluid mechanical characteristics. Mar Ecol Prog Ser 15:283-292

Kranck K (1980) Experiments on the significance of flocculation in the settling of fine-grained sediment in still water. Can J Earth Sci 17:1517-1526

Lucas MI, Newell RC, Shumway SE, Seiderer LJ, Bally R (1987) Particle clearance and yield in relation to bacterioplankton and suspended particulate availability in estuarine and open coast populations of the mussel Mytilus edulis. Mar Ecol Prog Ser 36:215-224

Milligan TG (1996). A laboratory assessment of the relative importance of turbulence, particle composition, and concentration in limiting maximal floc size and settling behaviour. MSc thesis, Dalhousie University, Halifax

Møhlenberg F, Riisgård HU (1978) Efficiency of particle retention in 13 species of suspension feeding bivalves. Ophelia 17:239-246

Ostroumov SA, Widdows J (2006) Inhibition of mussel suspension feeding by surfactants of three classes. Hydrobiologia 556:381-386

Editorial responsibility: Judith Grassle, New Brunswick, New Jersey, USA
Palmer RE, Williams LG (1980) Effect of particle concentration on filtration efficiency of the bay scallop Argopecten irradians and the oyster Crassostrea virginica. Ophelia 19:163-174

Randløv A, Riisgård HU (1979) Efficiency of particle retention and filtration rate in four species of ascidians. Mar Ecol Prog Ser 1:55-59

Riisgård HU (1977) On measurements of the filtration rates of suspension feeding bivalves in a flow system. Ophelia 16:167-173

Riisgård HU (1988) Efficiency of particle retention and filtration rate in 6 species of northeast American bivalves. Mar Ecol Prog Ser 45:217-223

Riisgård HU, Seerup DF (2003) Filtration rates in the soft clam Mya arenaria: effects of temperature and body size. Sarsa 88:415-428

Rosa M, Ward JE, Shumway SE, Wilkfors GH, Espinosa EP, Allam B (2013) Effects of particle surface properties on feeding selectivity in the eastern oyster Crassostrea virginica and the blue mussel Mytilus edulis. J Exp Mar Biol Ecol 446:320-327

Rosa M, Ward JE, Ouvrard M, Holohan BA, Espinosa EP, Shumway SE, Allam B (2015) Examining the physiological plasticity of particle capture by the blue mussel, Mytilus edulis (L.): confounding factors and potential artifacts with studies utilizing natural seston. J Exp Mar Biol Ecol 473:207-217

Shumway SE (ed) (2011) Shellfish aquaculture and the environment. Wiley-Blackwell, Chichester

Silverman H, Lynn JW, Dietz TH (1996) Particle capture by the gills of Dreissena polymorpha: structure and function of the latero-frontal cirri. Biol Bull 191:42-54

Stenton-Dozey JME, Brown AC (1992) Clearance and retention efficiency of natural suspended particles by the rock-pool bivalve Venerupis corrugatus in relation to tidal availability. Mar Ecol Prog Ser 82:175-186

Strohmeier T, Strand Ø, Cranford P (2009) Clearance rates of the great scallop (Pecten maximus) and blue mussel (Mytilus edulis) at low natural seston concentrations. Mar Biol 156:1781-1795

Strohmeier T, Strand $\varnothing$, Alunno-Bruscia M, Duinker A, Cranford PJ (2012) Variability in particle retention efficiency by the mussel Mytilus edulis. J Exp Mar Biol Ecol 412:96-102

Strohmeier T, Strand $\varnothing$, Alunno-Bruscia M, Duinker A and others (2015) Response of Mytilus edulis to enhanced phytoplankton availability by controlled upwelling in an oligotrophic fjord. Mar Ecol Prog Ser 518:139-152

Vahl O (1972) Efficiency of particle retention in Mytilus edulis L. Ophelia 10:17-25

Ward JE, Shumway SE (2004) Separating the grain from the chaff: particle selection in suspension- and depositfeeding bivalves. J Exp Mar Biol Ecol 300:83-130

Ward JE, Sanford LP, Newell RIE, MacDonald BA (1998) A new explanation of particle capture in suspension-feeding bivalve molluscs. Limnol Oceanogr 43:741-752

Widdows J, Fieth P, Worrall CM (1979) Relationships between seston, available food and feeding activity in the common mussel Mytilus edulis. Mar Biol 50:195-207

Wilkinson L, Blank G, Gruber C (1996) Desktop data analysis with SYSTAT. Prentice Hall, Upper Saddle River, NJ

Williams LG (1982) Mathematical analysis of the effects of particle retention efficiency on determination of filtration rate. Mar Biol 66:171-177

Submitted: January 20, 2016; Accepted: June 30, 2016

Proofs received from author(s): August 2, 2016 